\title{
Proceeding
}

Supplementary Issue: Spring Conferences of Sports Science. Costa Blanca Sports Science Events, 19-20 June 2020. Alicante, Spain.

\section{Physical performance changes during circuit training and detraining in U15 soccer players}

\author{
LOURIVAL VIANNA ${ }^{1,2} \triangle$, DIOGO L. MARQUES ${ }^{2}$, MÁRIO C. MARQUES ${ }^{2,3}$, RICARDO FERRAZ2,3,4 \\ ${ }^{1}$ Research Center in Business Sciences (NECE), University of Beira Interior, Covilhã, Portugal \\ ${ }^{2}$ Department of Sport Sciences, University of Beira Interior, Covilhã, Portugal \\ ${ }^{3}$ Research Centre in Sports, Health and Human Development (CIDESD), Covilhã, Portugal \\ ${ }^{4}$ Castelo Branco Football Association, Castelo Branco, Portugal
}

\begin{abstract}
On-field soccer conditioning programs are effective to improve physical performance in soccer players. However, the effects of an in-season soccer-specific circuit during regular soccer training is still limited. Thus, this study aimed to analyse the effects of a soccer-specific circuit, followed by 4-weeks of detraining on physical performance in U15 soccer players. Twenty participants (13.3 \pm 0.5 years) were involved in this study. A soccer-specific circuit ( 15-min) performed without ball was applied three times per week and included sprints, changes of direction, jumps and skipping's. Before and after 6-weeks, as well as after detraining, the outcome measures included: countermovement jump, repeated sprint ability, yo-yo intermittent recovery test level 1 , change of direction and the 300-m modified shuttle-run test. After 6-weeks, repeated measures ANOVA revealed significant gains $(p<.05)$ in almost variables, except for the percent sprint decrement in the repeated sprint ability test. After detraining, significant decreases $(p<.05)$ were observed in almost variables, except for the countermovement jump best height and the repeated sprint ability best time. The results demonstrated that an in-season soccer-specific circuit was effective to improve physical performance in U15 soccer players. Nonetheless, 4-weeks of detraining is enough to revert the positive training-induced adaptations.
\end{abstract}

Keywords: Circuit training; Physical performance; Soccer; Training cessation; Youth.

Cite this article as:

Vianna, L., Marques, D.L., Marques, M.C., \& Ferraz, R. (2020). Physical performance changes during circuit training and detraining in U15 soccer players. Journal of Human Sport and Exercise, 15(3proc), S708-S722. doi:https://doi.org/10.14198/jhse.2020.15.Proc3.22

Corresponding author. Research Center in Business Sciences (NECE), University of Beira Interior, Covilhã, Portugal. https://orcid.org/0000-0003-3821-5130

E-mail: lourivalvianna@gmail.com

Supplementary Issue: Spring Conferences of Sports Science. Costa Blanca Sports Science Events, 19-20 June 2020. Alicante, Spain.

JOURNAL OF HUMAN SPORT \& EXERCISE ISSN 1988-5202

(C) Faculty of Education. University of Alicante

doi:10.14198/jhse.2020.15.Proc3.22

S708 | 2020| Proc3 | VOLUME 15

(c) 2020 University of Alicante 


\section{INTRODUCTION}

In soccer, the aerobic system is associated with the capacity to recover efficiently between intense efforts, while the anaerobic system is related to the ability to perform high-intensity intermittent actions, such as sprints, jumps, changes of direction, dribbles, shots and tackles (Stølen, Chamari, Castagna, \& Wisløff, 2005). Although soccer is mostly an aerobic game, the supply of anaerobic energy is linked with the most decisive actions (Stølen et al., 2005). In youth soccer, aerobic and anaerobic tests are used for detect talents and to discriminate elite from non-elite players (Vaeyens et al., 2006). Young elite soccer players (12-19 years) cover higher distances and present higher maximal oxygen consumption $\left(\mathrm{VO}_{2 \max }\right)$ values in comparison to non-elite peers (Rebelo et al., 2013; Strøyer, Hansen, \& Klausen, 2004; Vaeyens et al., 2006). In addition, they also perform better on sprinting, jumping, changing direction and repeated sprinting compared to non-elite players (Gravina et al., 2008; Rebelo et al., 2013; Vaeyens et al., 2006). Thus, even in young players, a well-developed physical condition is a prerequisite to play at an elite level (Vanderford, Meyers, Skelly, Stewart, \& Hamilton, 2004).

Although high-intensity interval training or small-sided games improve aerobic performance in young soccer players (McMillan, Helgerud, Macdonald, \& Hoff, 2005; Sperlich et al., 2011), it seems that they have little or no impact on sprinting, repeated sprinting and jumping in this age (Kunz, Engel, Holmberg, \& Sperlich, 2019). Thus, resistance training, plyometric training or a combination between both are suggested as a complement to improve physical condition in young soccer players (M. C. Marques, Pereira, Reis, \& van den Tillaar, 2013; Rodriguez-Rosell, Franco-Marquez, Mora-Custodio, \& Gonzalez-Badillo, 2016). Nonetheless, considering the financial costs associated with the implementation of resistance training, coaches opt to integrate the strength and plyometric exercises on the soccer-field during training sessions (M. C. Marques et al., 2013; Wong, Chamari, \& Wisloff, 2010).

On-field soccer conditioning programs must be designed based on the physical demands of the game, including a structure and sequence of exercises that stress both bioenergetic systems (Turner \& Stewart, 2014). Circuit training programs incorporate a set of anaerobic exercises with sport-specific movements performed consecutively, with short or no rest in between, to promote aerobic adaptations (Taşkin, 2009). Due to its short duration, it can be easily applied after the warm-up to prepare the players for the technicaltactical exercises. To our knowledge, only one study analysed the effects of a 3-week pre-season soccerspecific circuit training on sprint and change of direction performance in male elite soccer players ( 19 years) (Jullien et al., 2008). The circuit ( 12 min) was performed 5 times per week and was constituted by change of direction obstacles with and without ball, jumps, skipping and running. After 3-weeks, the change of direction ability and the coordination increased, but not the sprint performance (Jullien et al., 2008).

Although the training was effective to improve anaerobic parameters during pre-season, it is unknown whether in-season soccer-specific circuit is effective to improve aerobic and anaerobic performance in young soccer players. Moreover, the consequences of interrupt the physical training should also be investigated, since this topic presents divergent findings within the literature in young soccer players. While some studies observed decreases in physical performance in young soccer players (11-15 years) after detraining (Melchiorri et al., 2014; Meylan, Cronin, Oliver, Hopkins, \& Contreras, 2014), others found a maintenance (Diallo, Dore, Duche, \& Van Praagh, 2001). Thus, future studies should analyse the effects of a soccerspecific circuit on aerobic and anaerobic parameters in young soccer players, as well as the impact of a cessation period. 
Considering the importance for coaches to implement effective (results) and efficient (time) on-field soccer conditioning programs, this study aimed to analyse the effects of a 6-week soccer-specific circuit training, followed by detraining on physical performance in male U15 soccer players. We hypothesized that after 6weeks, physical performance would significantly improve, and a cessation period of 4-weeks would significantly decrease physical performance.

\section{MATERIAL AND METHODS}

\section{Study design}

This was a case study design implemented in a regional soccer team during the second half of the competitive season (i.e., January-April). During the intervention, the participants performed three soccer training sessions per week and a soccer game at the weekend. In general, the soccer training sessions lasted 90 min, and encompassed a 15-min warm-up (e.g., running, mobility exercises, rondo game, dynamic stretching), 15-min of a soccer-specific circuit, 35-min of technical-tactical training (e.g., passing and dribbling drills, ball possession), 20-min of strategic aspects of the game (e.g., set pieces), and a 5-min cool-down (dynamic stretching). We assessed the participants before (pre-test) and immediately after 6 -weeks (post-test), as well as after 4-weeks of the training program cessation (detraining). One-week before the initial tests, all participants underwent two familiarization sessions to ensure proper execution in all tests and minimize technical errors. The physical performance tests included vertical jumps, repeated sprints, intermittent runs and changes of direction. All tests were performed during the soccer training sessions schedule (i.e., 6:308:00 pm), in the same place, under the supervision of two researchers.

\section{Participants}

23 young male soccer players volunteered to participate in the study. The participants had to complete all testing sessions and have an attendance rate of $85 \%$ in the soccer training sessions (i.e., 15 in 18) to be included in the final analysis. From the initial sample, three participants were excluded due to being absent from more than 3 training sessions and/or missing the evaluations. The final sample was composed by 20 participants (age $13.3 \pm 0.5$ years, body mass $52.2 \pm 10.6 \mathrm{~kg}$, height $1.63 \pm 0.1 \mathrm{~m}$ ), with a soccer training experience of $6.3 \pm 2.5$ years. The technical staff, players and parents received detailed information regarding the nature of the study prior to its commencement. Both players and parents provided a written informed consent document, which was approved by the Ethics Committee responsible of the Department of Sport Sciences in the University of Beira Interior. All procedures were conducted according to the Declaration of Helsinki.

\section{Procedures}

All tests were carried out during one-week in three different sessions, separated by 48-h rest. The first session was used to measure anthropometry, the countermovement jump (CMJ) height and the repeated sprint ability (RSA). The second session was used to apply the Yo-Yo Intermittent Recovery Test Level 1 (YYIR1). The third session was used to measure the change of direction speed (CODS) and the anaerobic endurance. Before each session, we applied a warm-up protocol of 5-min submaximal run, followed by 3-5 sprints with progressive increase in velocity, 2 sets of 5 repetitions of vertical jumps, and dynamic stretching (high knees, butt kicks, closed and open knees, hamstring kicks, leg swing towards the opposite side and walking hip, quadriceps, and hamstring stretch) (D. L. Marques et al., 2019). Anthropometry and CMJ were measured inside the club facilities, while the other tests were conducted on an artificial-turf soccer field. During the tests, we verbally encouraged the participants to give a maximal effort. 


\section{Anthropometry}

The body mass, in kg, (TANITA BC-601, Japan) and the height, in $\mathrm{m}$, (Portable stadiometer SECA 213, Germany) were measured with precisions of $0.1 \mathrm{~kg}$ and $0.1 \mathrm{~m}$, respectively. Body mass index (BMI) was calculated by dividing body mass by the height squared $\left(\mathrm{kg} / \mathrm{m}^{2}\right)$.

\section{Countermovement Jump Height}

From a stand position with the feet shoulder width apart and the hands on the hips, we instructed the participants to perform a rapid downward movement into a squat position, immediately followed by a rapid vertical jump as high as possible. Three CMJ were performed, interspersed by 30 -s rest (D. L. Marques et al., 2019). A specific warm-up of 3 submaximal CMJ was performed, with a 10-s rest between repetitions. The CMJ height was estimated based on the measurement of the flight time using an infrared timing system (Optojump System, Microgate, Italy). We analysed the mean value of the three jumps $\left(\mathrm{CMJ}_{\text {mean }}\right.$ ) and the best jump (CMJ best). The coefficient of variation (CV) was $3.4 \%$ and the intraclass correlation coefficient (ICC) was 0.88 (95\% confidence interval, $\mathrm{Cl}: 0.81-0.92)$.

\section{Repeated Sprint Ability Test}

The RSA was measured using the Bangsbo Sprint Test (Bangsbo, Nørregaard, \& Thorsø, 1991). Positioned one-meter behind the starting line, we instructed the participants to perform 7 sprints of $34.2-\mathrm{m}$, interspersed by an active recovery of 25-s. A specific warm-up of two submaximal 34.2-m sprints was performed, interspersed by 30-s rest. The time was measured using photoelectric cells (RaceTime Kit 2, Microgate, Italy). The variables collected for analysis were the sum of all sprints times ( $\left.R S A_{\text {total }}\right)$, the mean sprint time (RSA $\left.A_{\text {mean }}\right)$, the best sprint time (RSA best), and the percent sprint decrement $\left(\mathrm{S}_{\mathrm{dec}}\right)$, which was calculated as follows: $S_{\text {dec }}(\%)=($ worst sprint time/best sprint timex100)-100 (Torres-Torrelo et al., 2018). The CV was $2.7 \%$ and the ICC was 0.93 (Cl: 0.91-0.96).

\section{Yo-Yo Intermittent Recovery Test Level 1}

The YYIR1 was performed using the procedures described by Krustrup et al. (2003). We instructed the participants to perform two 20-m runs back and forth between the starting, turning and finishing line, at a progressively increased velocity, which was controlled by audio beeps from an application. Between the two 20 -m runs it was provided an active recovery of 10-s. When the participants failed twice to reach the finishing line in time, the test ended, and the total distance was kept for analysis. The $\mathrm{VO}_{2 \max }$ was estimated using the following equation: $\mathrm{VO}_{2 \max }(\mathrm{mL} / \mathrm{min} / \mathrm{kg})=\mathrm{YYIR} 1$ distance $(\mathrm{m}) \times 0.0084+36.4$ (Bangsbo, laia, \& Krustrup, 2008).

\section{Change of Direction Speed Test}

The CODS was measured using the original dimensions of the Illinois Agility Test (Getchell, 1979), and a modified version regarding the starting position. Instead of starting from a prone position, we instructed the participants to start from a standing position, since the former is not specific to soccer (Hachana et al., 2014). Before the test, we set up an area of 10-m long and 5-m wide with 4 cones. In the centre of the area, we placed 4 cones 3.3-m apart (Figure 1). After our instruction, the participants sprinted 10-m from cone $A$ to cone $B$, turned around the cone $B$ and sprinted $10-m$ to cone $C$, swerved in and out of four cones back and forth, turned around cone $C$ and sprinted $10-\mathrm{m}$ to cone $\mathrm{G}$, turned around the cone $\mathrm{G}$ and sprinted $10-\mathrm{m}$ to cone $\mathrm{H}$. Two trials were conceived, interspersed by 1-min rest. Before the test, they performed one submaximal trial. The time was measured using photoelectric cells (RaceTime Kit 2, Microgate, Italy). We analysed the mean value of the two trials (CODS mean $)$ and the best time (CODS best $_{\text {bi }}$. The CV was $2.3 \%$ and the ICC was 0.80 (Cl: 0.62-0.89). 

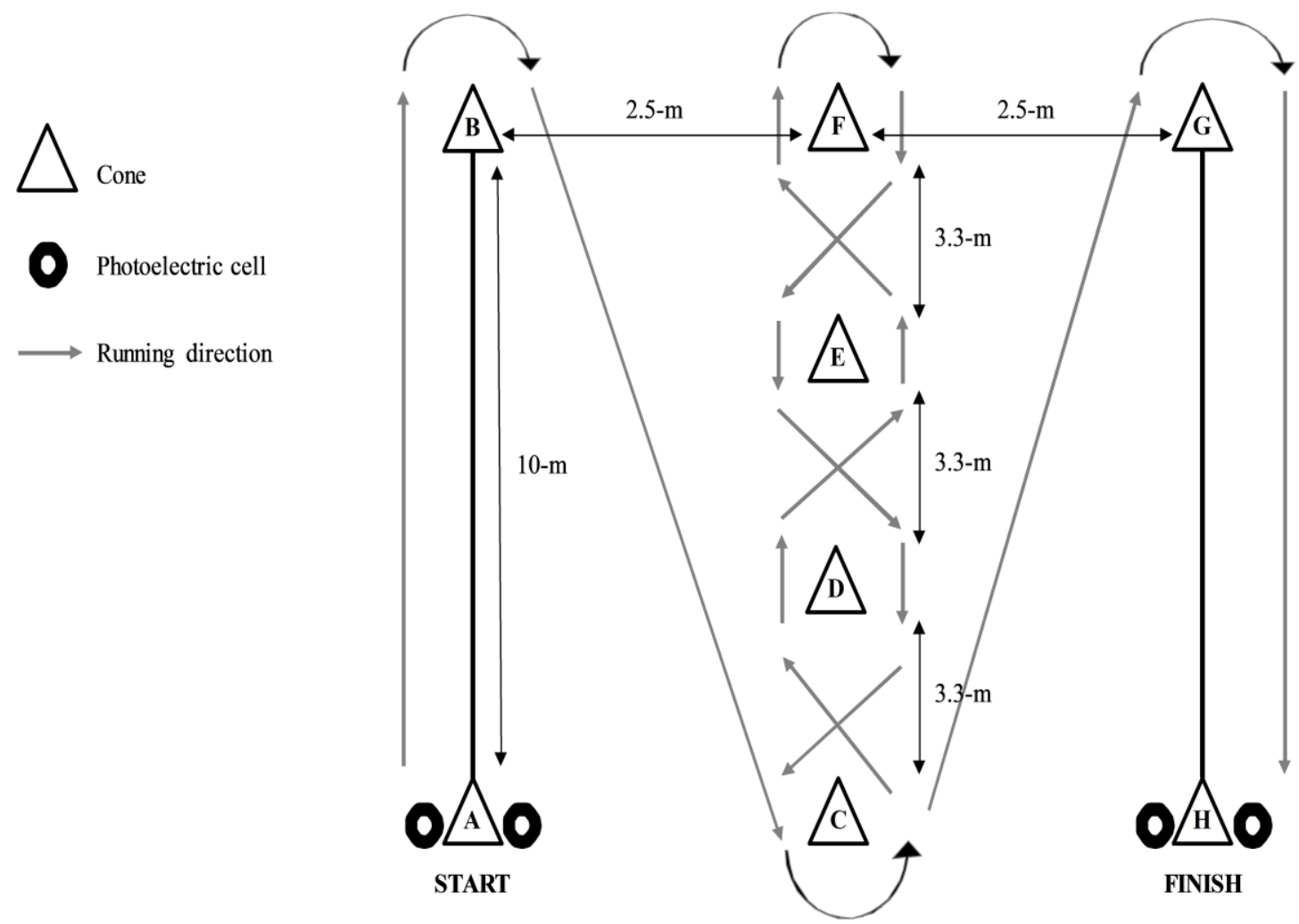

Figure 1. Change of Direction Speed Test. Adapted from Getchell (1979).

\section{0-m Modified Shuttle Run Test}

Anaerobic endurance was measured using a modified version of the 300-m Shuttle Run Test (300-m MSR). The original version consists of 15 sprints between two 20-m lines until reaching a total distance of 300-m (Moore \& Murphy, 2003). As young soccer players perform sprints from 5 to $40-\mathrm{m}$ during a game (Al Haddad, Simpson, Buchheit, Di Salvo, \& Mendez-Villanueva, 2015), we modified the structure of the test according to the game specificity. We placed six cones every $10-\mathrm{m}$, until completing $50-\mathrm{m}$ (Figure 2). After our instruction, the participants sprinted until each one of the five distances and returned to the starting line. One trial was conceived to perform the test. Before the test, they performed a submaximal trial. We measured the time using a digital stopwatch (Casio HS-3V-1R, Japan), and the total time was kept for further analysis.

\section{Soccer-Specific Circuit Training}

Over 6-weeks, the participants performed the circuit training during the soccer sessions three times per week on non-consecutive days (48-h rest). After a 15-min general warm-up, the participants performed a modified version of a soccer-specific circuit designed by Ferraz, van den Tillaar, and Marques (2012). The original circuit was designed for senior soccer players ( 27 years) and lasts on average $90 \mathrm{~s}$ per participant, thus we reduced the time to $38.5 \pm 2.5 \mathrm{~s}$ considering the age of the players. The circuit was performed without ball and was constituted by multiple changes of direction, slow running, sprints, jumps, trotting and skipping's. The participants repeated the circuit three times. At the end of the circuit 1, they performed 10 squats, while after the circuit 2, they executed 5 maximal CMJ, and when they finished the circuit 3 , they did 30 sit-ups (Figure 3). Between sets it was provided a 2-min rest. Altogether, the circuit training lasted $\sim 15$-min. We strongly encouraged the players to perform the exercises as forcefully and fast as possible with proper technique. 


$$
\bigwedge_{\text {Cone }}
$$

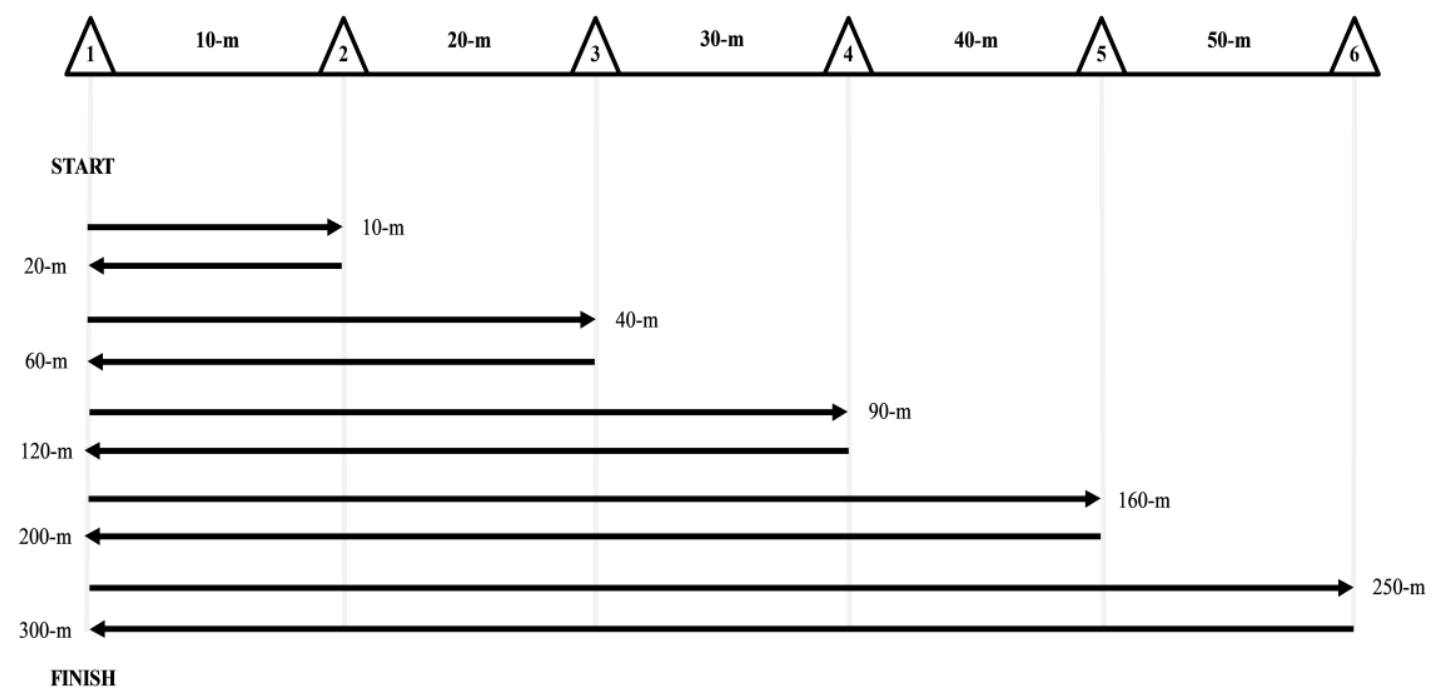

Figure 2. 300-m Modified Shuttle Run Test. Adapted from Moore and Murphy (2003).

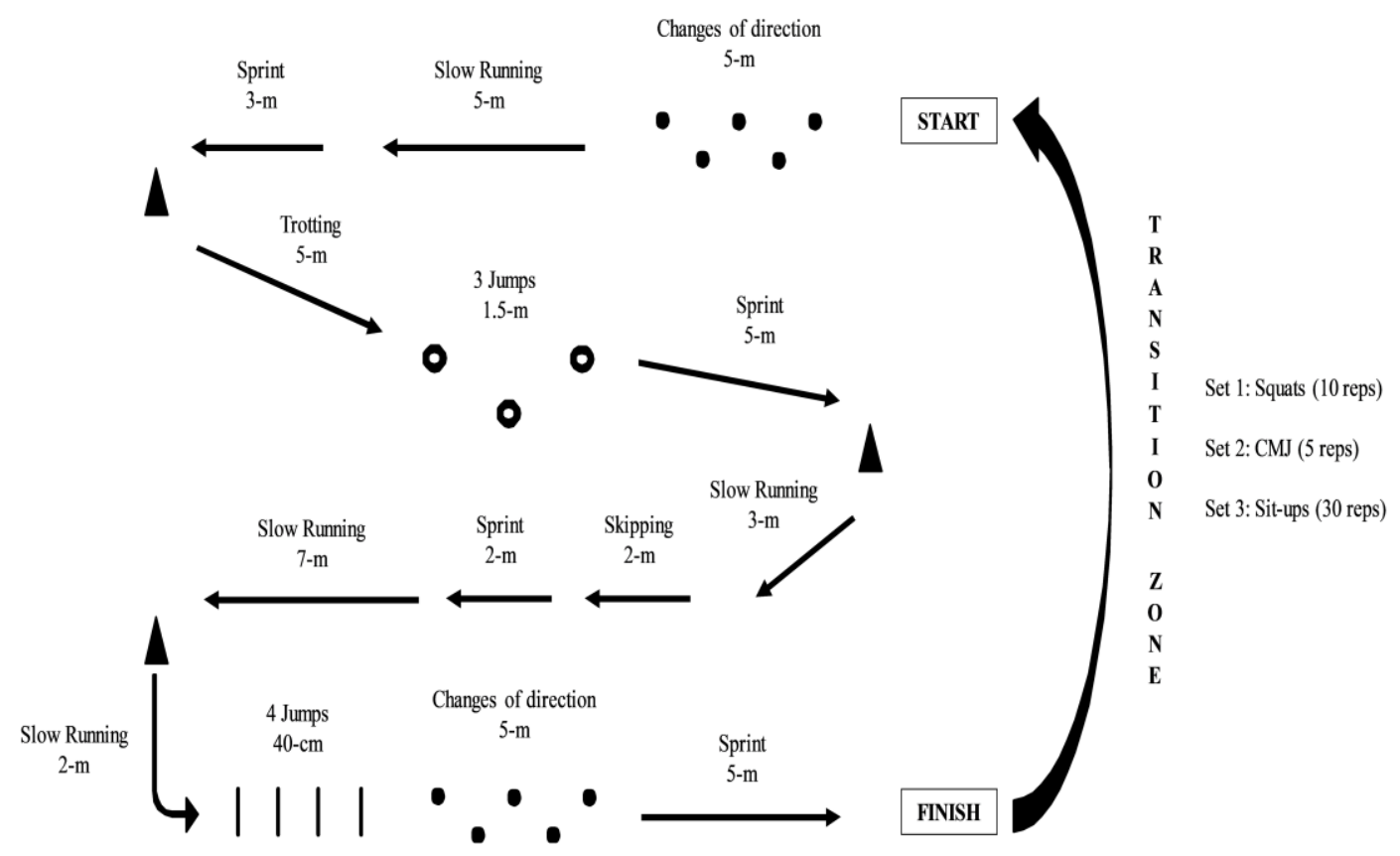

Figure 3. Illustration of the Soccer-Specific Circuit. Adapted from Ferraz et al. (2012). 


\section{Statistical Analysis}

Data are presented as mean \pm SD unless otherwise indicated. The normality and homoscedasticity were analysed using the Shapiro-Wilk and Levene tests, respectively. The ICC $(95 \% \mathrm{CI})$ was calculated using a two-way random average measures absolute agreement model $(2, \mathrm{k})$, while the CV was calculated as ([SD/mean] x 100). A repeated measures ANOVA with post-hoc Bonferroni adjustments was performed to detect differences between the three moments (pre-test vs. post-test vs. detraining). The percent change ( $\Delta$ $(\%)=([$ Post-test-Pre-test $]$ Pre-test $) \times 100)$ was calculated with a $90 \% \mathrm{Cl}$. The effect sizes (ES) were calculated based on the Hedge's $g$ formula (Hedges \& Olkin, 1985) and interpreted as follows: trivial $(g<$ $0.2)$, small $(g=0.2-0.6)$, moderate $(g=0.6-1.2)$, large $(g=1.2-2.0)$, very large $(g=2.0-4.0)$ and extremely large $(g>4.0)$ (Hopkins, Marshall, Batterham, \& Hanin, 2009). The alpha level was set at $p<.05$. Statistical data were analysed using SPSS v26 (SPSS Inc., USA).

\section{RESULTS}

Physical performance changes and the ES are presented in Table 1 and 2, respectively.

\section{Anthropometry}

After 6-weeks, we observed a significant increase in body mass $(3.2 \%)$, height $(0.9 \%)$, and BMI $(1.3 \%)$. Following the detraining, we found significant increases in body mass $(1.4 \%)$ and height $(0.6 \%)$. From pretest to detraining, we observed significant increases in body mass (4.6\%), height (1.5\%), and BMI (1.5\%).

\section{Countermovement Jump Height}

In post-test, we observed significant increases in $\mathrm{CMJ}_{\text {mean }}(11.7 \%)$ and $\mathrm{CMJ}_{\text {best }}(11.3 \%)$. After the detraining, we observed a significant decrease in $\mathrm{CMJ}_{\text {mean }}(-4.6 \%)$. From pre-test to detraining, we found significant increases in $\mathrm{CMJ}_{\text {mean }}(6.4 \%)$ and $\mathrm{CMJ}_{\text {best }}(8.0 \%)$.

\section{Repeated Sprint Ability Test}

After the circuit training, we observed significant decreases in $\mathrm{RSA}_{\text {total }}(-4.2 \%), \mathrm{RSA}_{\text {mean }}(-4.2 \%)$ and $\mathrm{RSA}$ best $(-3.8 \%)$. After the detraining, we found significant increases in $\mathrm{RSA}_{\text {total }}(2.5 \%), \mathrm{RSA}_{\text {mean }}(2.5 \%)$, and $\mathrm{S}_{\text {dec }}$ $(79.7 \%)$. From pre-test to detraining, we observed significant decreases in $\mathrm{RSA}_{\text {total }}(-1.9 \%), \mathrm{RSA}_{\text {mean }}(-1.9 \%)$ and $\operatorname{RSA}_{\text {best }}(-3.5 \%)$.

\section{Yo-Yo Intermittent Recovery Test Level 1}

After 6-weeks, we observed significant increases in YYIR1 distance (46.4\%) and $\mathrm{VO}_{2 \max }(6.7 \%)$. Following the detraining, we found significant decreases in YYIR1 distance $(-14.1 \%)$ and $\mathrm{VO}_{2 \max }(-3.1 \%)$. From pre-test to detraining, we observed significant increases in YYIR1 distance $(23.6 \%)$ and $\mathrm{VO}_{2 \max }(3.3 \%)$.

\section{Change of Direction Speed Test}

After the training program, we observed significant decreases in CODS mean $_{(-3.9 \%)}$ and CODS best $(-3.4 \%)$. From post-test to detraining, we found significant increases in CODS $_{\text {mean }}(1.5 \%)$ and CODS best $(1.7 \%)$. From pre-test to detraining, we observed significant decreases in $\operatorname{CODS}_{\text {mean }}(-2.5 \%)$ and $\operatorname{CODS}_{\text {best }}(-1.5 \%)$.

\section{0-m Modified Shuttle Run Test}

After 6-weeks, we found significant decreases in the time to complete the 300-m MSR test (-6.2\%), and after the detraining a significant increase $(4.6 \%)$. 
Table 1. Changes in variables from pre- to post-test, from post-test to detraining, and from pre-test to detraining.

\begin{tabular}{|c|c|c|c|c|c|c|}
\hline Variable & $\begin{array}{l}\text { Pre-test } \\
\text { (mean } \pm \mathrm{SD} \text { ) }\end{array}$ & $\begin{array}{l}\text { Post-test } \\
\text { (mean } \pm \text { SD) }\end{array}$ & $\begin{array}{l}\Delta \text { pre-post } \\
(C \mid 90 \%)\end{array}$ & $\begin{array}{l}\text { Detraining } \\
\text { (mean } \pm \mathrm{SD} \text { ) }\end{array}$ & $\begin{array}{l}\Delta \text { post-detraining } \\
(\mathrm{Cl} \mid 90 \%)\end{array}$ & $\begin{array}{l}\Delta \text { pre-detraining } \\
(\mathrm{C} \mid 90 \%)\end{array}$ \\
\hline Body mass (kg) & $52.23 \pm 10.65$ & $53.89 \pm 10.98^{* * *}$ & $3.2(2.7$ to 3.7$)$ & $54.53 \pm 10.49$ \#††† & $1.4(0.9$ to 1.8$)$ & 4.6 (3.9 to 5.3$)$ \\
\hline Height (m) & $1.63 \pm 0.08$ & $1.64 \pm 0.08 * * *$ & $0.9(0.8$ to 1.1$)$ & $1.65 \pm 0.08 \mathrm{\# + \dagger †}$ & 0.6 (0.5 to 0.7$)$ & 1.5 (1.4 to 1.7$)$ \\
\hline $\mathrm{BMI}\left(\mathrm{kg} / \mathrm{m}^{2}\right)$ & $19.49 \pm 2.54$ & $19.74 \pm 2.59$ * & $1.3(0.7$ to 1.9$)$ & $19.76 \pm 2.49 \dagger$ & $0.2(-0.3$ to 0.7$)$ & $1.5(0.8$ to 2.1$)$ \\
\hline $\mathrm{CMJ}_{\text {mean }}(\mathrm{cm})$ & $27.06 \pm 4.40$ & $30.16 \pm 4.93^{* * *}$ & $11.7(9.5$ to 13.9$)$ & $28.65 \pm 4.33 \mathrm{\# \# † \dagger}$ & $-4.6(-6.3$ to -2.9$)$ & $6.4(4.0$ to 8.8$)$ \\
\hline $\mathrm{CMJ}_{\text {best }}(\mathrm{cm})$ & $27.86 \pm 4.46$ & $30.95 \pm 4.98^{* * *}$ & $11.3(9.0$ to 13.6$)$ & $29.90 \pm 4.31 \mathrm{\dagger \dagger \dagger}$ & $-2.9(-4.8$ to -0.9$)$ & 8.0 (5.4 to 10.6$)$ \\
\hline $\mathrm{RSA}_{\text {total }}(\mathrm{s})$ & $44.84 \pm 1.58$ & $42.93 \pm 1.90^{* * *}$ & $-4.2(-5.1$ to -3.4$)$ & $43.97 \pm 1.73$ \#† & 2.5 (1.5 to 3.5$)$ & $-1.9(-2.9$ to -0.9$)$ \\
\hline $\mathrm{RSA}_{\text {mean }}(\mathrm{s})$ & $6.41 \pm 0.23$ & $6.13 \pm 0.27^{* * *}$ & $-4.2(-5.1$ to -3.4$)$ & $6.28 \pm 0.25 \mathrm{\# \#}$ & 2.5 (1.5 to 3.5$)$ & $-1.9(-2.9$ to -0.9$)$ \\
\hline $\mathrm{RSA}_{\text {best }}(\mathrm{s})$ & $6.18 \pm 0.19$ & $5.95 \pm 0.24^{* * *}$ & $-3.8(-4.6$ to -2.9$)$ & $5.96 \pm 0.30 \dagger \dagger$ & $0.3(-1.1$ to 1.6$)$ & $-3.5(-4.8$ to -2.2$)$ \\
\hline $\mathrm{S}_{\mathrm{dec}}(\%)$ & $7.59 \pm 2.40$ & $6.25 \pm 2.32$ & $-11.1(-22.6$ to 0.4$)$ & $9.96 \pm 5.15 \#$ & 79.7 (42.4 to 116.9$)$ & $57.6(17.1$ to 98.1$)$ \\
\hline YYIR1 (m) & $755.00 \pm 274.68$ & $1101.00 \pm 429.02^{* * *}$ & 46.4 (38.4 to 54.5$)$ & $926.00 \pm 388.04 \mathrm{\# \# † \dagger}$ & $-14.1(-19.0$ to -9.2$)$ & 23.6 (16.7 to 30.6$)$ \\
\hline YYIR1 (mL/min/kg) & $42.74 \pm 2.31$ & $45.65 \pm 3.60^{* * *}$ & 6.7 (5.4 to 8.0) & $44.18 \pm 3.26 \mathrm{\# \# \dagger †}$ & $-3.1(-4.3$ to -1.9$)$ & 3.3 (2.1 to 4.6$)$ \\
\hline $\mathrm{CODS}_{\text {mean }}(\mathrm{s})$ & $18.10 \pm 0.82$ & $17.38 \pm 0.75^{* * *}$ & $-3.9(-4.8$ to -3.0$)$ & $17.63 \pm 0.79 \#+$ & 1.5 (0.8 to 2.1$)$ & $-2.5(-3.6$ to -1.5$)$ \\
\hline $\mathrm{CODS}_{\text {best }}(\mathrm{s})$ & $17.73 \pm 0.81$ & $17.11 \pm 0.72^{* * *}$ & $-3.4(-4.3$ to -2.5$)$ & $17.39 \pm 0.80 \#$ & $1.7(1.0$ to 2.4$)$ & $-1.8(-2.9$ to -0.8$)$ \\
\hline 300-m MSR (s) & $70.74 \pm 6.26$ & $66.13 \pm 3.76^{* * *}$ & $-6.2(-7.7$ to -4.7$)$ & $69.11 \pm 4.07$ \#\# & 4.6 (3.5 to 5.6$)$ & $-2.0(-3.5$ to -0.4$)$ \\
\hline
\end{tabular}

A: percent change; BMI: body mass index; CMJ: countermovement jump; RSA: repeated-sprint ability; Sdec: percent sprint decrement; YYIR1: yo-yo intermittent recovery test level 1; CODS: change of direction speed; 300-m MSR: 300-m modified shuttle-run test; Significant differences from pre- to post-test: ${ }^{*} p<.05$; ${ }^{* *} p<0.1$; ${ }^{* * *} p<.001$; Significant differences from post-test to detraining: $\#<.05 ; \# p<.01 ; \# \# p<.001$; Significant differences from pre-test to detraining: $t p<.05 ; t+p<.01 ; t+\uparrow p<.001$. 
Table 2. Magnitude of within-subject changes in the different moments.

\begin{tabular}{|c|c|c|c|}
\hline Variable & $\begin{array}{l}\text { Pre- to post-test } \\
\text { ES (classification) }\end{array}$ & $\begin{array}{l}\text { Post-test to detraining } \\
\text { ES (classification) }\end{array}$ & $\begin{array}{l}\text { Pre-test to detraining } \\
\text { ES (classification) }\end{array}$ \\
\hline Body mass $(\mathrm{kg})$ & 0.15 (trivial) & 0.06 (trivial) & 0.21 (small) \\
\hline Height (m) & 0.17 (trivial) & 0.12 (trivial) & 0.29 (small) \\
\hline $\mathrm{BMI}\left(\mathrm{kg} / \mathrm{m}^{2}\right)$ & 0.09 (trivial) & 0.01 (trivial) & 0.10 (trivial) \\
\hline $\mathrm{CMJ}_{\text {mean }}(\mathrm{cm})$ & 0.64 (moderate) & -0.31 (small) & 0.35 (small) \\
\hline $\mathrm{CMJ}_{\text {best }}(\mathrm{cm})$ & 0.63 (moderate) & -0.22 (small) & 0.45 (small) \\
\hline $\mathrm{RSA}_{\text {total }}(\mathrm{s})$ & -1.05 (moderate) & 0.55 (small) & -0.50 (small) \\
\hline $\mathrm{RSA}_{\text {mean }}(\mathrm{s})$ & -1.05 (moderate) & 0.55 (small) & -0.50 (small) \\
\hline $\mathrm{RSA}_{\text {best }}(\mathrm{s})$ & -1.03 (moderate) & 0.04 (trivial) & -0.83 (moderate) \\
\hline $\mathrm{S}_{\mathrm{dec}}(\%)$ & -0.55 (small) & 0.89 (moderate) & 0.57 (small) \\
\hline YYIR1 (m) & 0.92 (moderate) & -0.41 (small) & 0.49 (small) \\
\hline YYIR1 (mL/min/kg) & 0.92 (moderate) & -0.41 (small) & 0.49 (small) \\
\hline $\operatorname{CODS}_{\text {mean }}(\mathrm{s})$ & -0.88 (moderate) & 0.32 (small) & -0.56 (small) \\
\hline $\operatorname{cODS}_{\text {best }}(\mathrm{s})$ & -0.77 (moderate) & 0.36 (small) & -0.40 (small) \\
\hline 300-m MSR (s) & -0.86 (moderate) & 0.73 (moderate) & -0.30 (small) \\
\hline
\end{tabular}

ES: Hedge's g effect size; BMI: body mass index; CMJ: countermovement jump; RSA: repeated-sprint ability; Sdec: percent sprint decrement; YYIR1: yo-yo intermittent recovery test level 1; CODS: change of direction speed; 300-m MSR: 300-m modified shuttlerun test.

\section{DISCUSSION}

To our knowledge, this was the first study to analyse the effects of an in-season soccer-specific circuit, followed by detraining on physical performance in U15 soccer players. We observed that a soccer-specific circuit applied during the competitive period significantly improved aerobic and anaerobic endurance in U15 soccer players, and that a cessation period of 4-weeks was enough to significantly revert the positive traininginduced adaptations. Nonetheless, after the detraining period, the physical performance was better in comparison to the baseline values.

\section{Anthropometry}

The body mass, height and BMl significantly increased during all moments. These increases were expectable and can be justified by the age-specific growth and maturation (Meylan et al., 2014). Whether these changes were stimulated by the training program remain to be elucidated. Therefore, future studies including a control group with the same age are needed to confirm this observation.

\section{Countermovement Jump Height}

The circuit training significantly improved the CMJ height. These increases were stimulated by the horizontal jumps and squat jumps implemented in the circuit. Although this is the first study to apply a soccer-specific 
circuit in U15 soccer players, previous research also observed that conditioning programs using jump exercises were effective to improve the CMJ height (6-8\%) in 13-14 years old soccer players (M. C. Marques et al., 2013; Wong et al., 2010). Thus, young soccer players with low initial levels of strength significantly increase their lower body strength when exposed to conditioning programs (M. C. Marques et al., 2013). In our study, the detraining period significantly decreased the CMJ height. Indeed, previous research with young healthy boys (10-13 years) observed that a cessation period of 4-weeks resulted in decreases in CMJ height (Chaouachi et al., 2019). Thus, to prevent a decrease in the capacity to produce force rapidly, U15 soccer players need to maintain the training stimulus during the competitive period. Despite the significant losses in $\mathrm{CMJ}$ height after detraining, the players maintained their jumping performance better compared to the baseline levels. This could be associated with the growth and physical maturation of the participants, which can avoid a pronounced loss of muscle strength (Chaouachi et al., 2019).

\section{Repeated Sprint Ability Test}

After 6-weeks, most RSA parameters significantly improved. As other conditioning programs with young soccer players that included sprints (Buchheit, Mendez-Villanueva, Delhomel, Brughelli, \& Ahmaidi, 2010; Tønnessen, Shalfawi, Haugen, \& Enoksen, 2011), the circuit was also effective to increase the anaerobic performance. Thus, young soccer players can improve the RSA either by performing sprints in an isolated manner (Buchheit et al., 2010; Tønnessen et al., 2011), or in a more soccer specific way through a circuit training. After detraining it was observed a decrease in the $R S A_{\text {total }}, R S A_{\text {mean }}$ and $S_{\text {dec. }}$. A study with adult soccer players observed a decrease in the RSA total after a 2-week in-season detraining period, but an improvement in the $S_{\text {dec }}$ (Rodríguez-Fernández et al., 2018). Although the authors suggested that $S_{\text {dec }}$ is not sensitive to training cessation (Rodríguez-Fernández et al., 2018), the same cannot be stated in U15 soccer players. Considering that children and adolescents present a lower contribution of anaerobic glycolysis during high-intensity efforts compared to adults (Ratel, Duche, Hennegrave, Van Praagh, \& Bedu, 2002), probably the detraining period reduced the utilization rate of the glycogen during exercise, and consequently affected the capacity to perform repeated sprints in our participants. However, future studies are necessary to investigate this observation. Despite the significant decreases in the RSA after detraining, several RSA parameters remained better compared to baseline.

\section{Yo-Yo Intermittent Recovery Test Level 1}

It was observed significant gains in the distance and the estimated $\mathrm{VO}_{2 \max }$ in the YYIR1. The aerobic endurance plays a major role during a soccer game, specifically in the recovery process within and between high-intensity actions (Stølen et al., 2005). Thus, as circuit training programs are structured to increase the aerobic system through high-intensity actions performed consecutively with short or no rest between exercises (Taşkin, 2009), probably these gains were influenced by the soccer-specific circuit. Previous studies with young soccer players (14-16 years) also found significant increases in the $\mathrm{VO}_{2 \max }$, when the conditioning programs were of short-duration and included sprints (McMillan et al., 2005; Salah, Cavar M, \& Hofmann P, 2017; Sperlich et al., 2011). Nonetheless, our circuit was designed with sprints, changes of direction, jumps, and skipping's, to be more representative of the physical demands of the game. Future studies should compare the effectiveness of high-intensity interval training (sprint-based) and the soccerspecific circuit on aerobic performance in U15 soccer players. After detraining, it was observed significant decreases in the distance and the estimated $\mathrm{VO}_{2 \max }$ in the YYIR1. These results agree with previous findings with young soccer players (15 years), where a detraining period of 4-weeks was enough to significantly decrease the $\mathrm{VO}_{2 \max }$ (Melchiorri et al., 2014). Thus, coaches must avoid interrupting conditioning programs in young soccer players due to the detrimental effects on anaerobic endurance. The performance in the YYIR1 after detraining was better compared to the baseline values, which means that the aerobic endurance was not totally affected during this period. Future research should investigate the time needed to U15 soccer 
players return to the previous levels on the YYIR1 with retraining through the soccer-specific circuit after a detraining period.

\section{Change of Direction Speed Test}

The CODS significantly improved after 6-weeks. Although the CODS ability in young soccer players can be improved through resistance training, plyometric training, repeated sprints and small-sided games, the gains are higher when the conditioning programs include change of direction exercises (Chtara et al., 2017; Salah et al., 2017). Thus, our soccer-specific circuit can be considered an effective method to increase the CODS in U15 soccer players. Following detraining, the CODS ability significantly decreased. To our knowledge, no study analysed the effects of detraining on CODS in young soccer players, which means that future research is warranted. In a study that investigated the effects of an in-season plyometric training, followed by detraining on physical performance in junior male soccer players ( $\sim 17$ years), the authors observed that the ability to change of direction with ball during a dribbling speed test was not affected by a 4-week detraining period (Branquinho et al., 2020). Although these results may indicate that this quality can be preserved after the detraining, the findings are specific to the dribbling speed test. Thus, future research is necessary to investigate the effects of soccer-specific circuit, followed by detraining on CODS during a dribbling test in U15 soccer players. Despite the significant decreases after detraining, the CODS ability was significantly better compared to baseline.

\section{0-m Modified Shuttle Run Test}

Following the circuit training, the performance in the 300-m MSR test significantly increased. As succeeded in the RSA test, the soccer-specific circuit demonstrated to be effective to increase the anaerobic endurance in U15 soccer players. To our knowledge, only one study analysed the effects of an in-season conditioning program on anaerobic endurance, measured by the original version of the 300-m Shuttle Run Test, in U13 and U14 soccer players (Salah et al., 2017). In that study, one group performed the sprint interval training with changes of direction and other group a continuous running training (65\% of maximum heart rate). Both trainings were performed on the soccer field twice a week during 6-weeks (Salah et al., 2017). The authors observed that only the sprint training with changes of direction significantly improved the anaerobic endurance (Salah et al., 2017). Thus, including different training stimulus in the conditioning program, namely accelerations, decelerations and changes of direction, contributes to increase the anaerobic endurance in young soccer players. After the detraining, it was observed a significant decrease in anaerobic endurance. Indeed, according to literature, a training cessation alters some metabolic parameters with negative consequences in anaerobic endurance in young soccer players ( 15 years) (Melchiorri et al., 2014). Thus, coaches should maintain a proper training stimulus during the entire season through conditioning programs to continuously develop the anaerobic endurance in young soccer players.

\section{LIMITATIONS AND STRENGTHS}

This study presents some limitations such as the duration, the lack of a control group, the small sample size and the non-application of a soccer-specific test with ball to analyse the transference effect of the circuit training on technical skills. Thus, future studies must consider the above limitations and develop longitudinal studies with a control or another experimental group, increase the sample size, and administer a soccerspecific test with ball to further increase the understanding of the effects of the soccer-specific circuit training on physical and technical performance in young soccer players. Nonetheless, this study has some strengths, such as the presentation of a novel soccer-specific circuit quick and easy to administer on the soccer-field, and which can develop effectively the aerobic and anaerobic endurance in young soccer players. Moreover, 
the soccer-specific circuit is feasible and cost-effective, which can increase its capacity to be replicated by every soccer team, regardless of their financial capacity.

\section{CONCLUSION}

The present study demonstrated that an in-season soccer-specific circuit is effective and efficient to significantly improve aerobic and anaerobic endurance in U15 soccer players, and a 4-week training cessation is enough to significantly decrease the physical performance. Thus, coaches need to provide a specific training stimulus during the entire season through on-field soccer conditioning programs to improve aerobic and anaerobic endurance in U15 soccer players. In practical terms, a 15-min soccer-specific circuit integrated in the soccer training routines during the competitive period is effective to improve physical performance in U15 soccer players.

\section{ACKNOWLEDGEMENTS}

We wish to thank all the participants involved in this study. This work was supported by a grant from the Portuguese Foundation for Science and Technology, I.P. (SFRH/BD/147608/2019). All the experiments comply with the current laws of Portugal.

\section{CONFLICT OF INTEREST}

There are no conflicts of interest.

\section{REFERENCES}

Al Haddad, H., Simpson, B. M., Buchheit, M., Di Salvo, V., \& Mendez-Villanueva, A. (2015). Peak match speed and maximal sprinting speed in young soccer players: effect of age and playing position. Int J Sports Physiol Perform, 10(7), 888-896. https://doi.org/10.1123/ijspp.2014-0539

Bangsbo, J., laia, F. M., \& Krustrup, P. (2008). The Yo-Yo intermittent recovery test : a useful tool for evaluation of physical performance in intermittent sports. Sports Med, 38(1), 37-51. https://doi.org/10.2165/00007256-200838010-00004

Bangsbo, J., Nørregaard, L., \& Thorsø, F. (1991). Activity profile of competition soccer. Can J Sport Sci, 16(2), 110-116.

Branquinho, L., Ferraz, R., Mendes, P. D., Petricia, J., Serrano, J., \& Marques, M. C. (2020). The Effect of an In-Season 8-Week Plyometric Training Programme Followed By a Detraining Period on Explosive Skills in Competitive Junior Soccer Players. MJSSM, 9(1), 33-40. https://doi.org/10.26773/mjssm.200305

Buchheit, M., Mendez-Villanueva, A., Delhomel, G., Brughelli, M., \& Ahmaidi, S. (2010). Improving repeated sprint ability in young elite soccer players: repeated shuttle sprints vs. explosive strength training. J Strength Cond Res, 24(10), 2715-2722. https://doi.org/10.1519/jsc.0b013e3181bf0223

Chaouachi, A., Ben Othman, A., Makhlouf, I., Young, J. D., Granacher, U., \& Behm, D. G. (2019). Global Training Effects of Trained and Untrained Muscles With Youth Can be Maintained During 4 Weeks of Detraining. J Strength Cond Res, 33(10), 2788-2800. https://doi.org/10.1519/jsc.0000000000002606

Chtara, M., Rouissi, M., Haddad, M., Chtara, H., Chaalali, A., Owen, A., \& Chamari, K. (2017). Specific physical trainability in elite young soccer players: efficiency over 6 weeks' in-season training. Biol Sport, 34(2), 137-148. https://doi.org/10.5114/biolsport.2017.64587 
Diallo, O., Dore, E., Duche, P., \& Van Praagh, E. (2001). Effects of plyometric training followed by a reduced training programme on physical performance in prepubescent soccer players. J Sports Med Phys Fitness, 41(3), 342-348.

Ferraz, R., van den Tillaar, R., \& Marques, M. C. (2012). The effect of fatigue on kicking velocity in soccer players. J Hum Kinet, 35, 97-107. https://doi.org/10.2478/v10078-012-0083-8

Getchell, B. (1979). Physical fitness: A way of life (2 ed.). New York: John Wiley and Sons, Inc.

Gravina, L., Gil, S. M., Ruiz, F., Zubero, J., Gil, J., \& Irazusta, J. (2008). Anthropometric and physiological differences between first team and reserve soccer players aged 10-14 years at the beginning and end of the season. J Strength Cond Res, 22(4), 1308-1314. https://doi.org/10.1519/jsc.0b013e31816a5c8e

Hachana, Y., Chaabene, H., Ben Rajeb, G., Khlifa, R., Aouadi, R., Chamari, K., \& Gabbett, T. J. (2014). Validity and reliability of new agility test among elite and subelite under 14-soccer players. PLoS One, 9(4), e95773. https://doi.org/10.1371/journal.pone.0095773

Hedges, L. V., \& Olkin, I. (1985). Statistical Methods for Meta-Analysis. San Diego: Academic Press.

Hopkins, W. G., Marshall, S. W., Batterham, A. M., \& Hanin, J. (2009). Progressive statistics for studies in sports medicine and exercise science. Med Sci Sports Exerc, 41(1), 3-12. https://doi.org/10.1249/mss.0b013e31818cb278

Jullien, H., Bisch, C., Largouët, N., Manouvrier, C., Carling, C. J., \& Amiard, V. (2008). Does a short period of lower limb strength training improve performance in field-based tests of running and agility in young professional soccer players? J Strength Cond Res, 22(2), 404-411. https://doi.org/10.1519/isc.0b013e31816601e5

Krustrup, P., Mohr, M., Amstrup, T., Rysgaard, T., Johansen, J., Steensberg, A., . . Bangsbo, J. (2003). The yo-yo intermittent recovery test: physiological response, reliability, and validity. Med Sci Sports Exerc, 35(4), 697-705. https://doi.org/10.1249/01.mss.0000058441.94520.32

Kunz, P., Engel, F. A., Holmberg, H. C., \& Sperlich, B. (2019). A Meta-Comparison of the Effects of HighIntensity Interval Training to Those of Small-Sided Games and Other Training Protocols on Parameters Related to the Physiology and Performance of Youth Soccer Players. Sports Med Open, 5(1), 7. https://doi.org/10.1186/s40798-019-0180-5

Marques, D. L., Travassos, B., Sousa, A. C., Gil, M. H., Ribeiro, J. N., \& Marques, M. C. (2019). Effects of Low-Moderate Load High-Velocity Resistance Training on Physical Performance of Under-20 Futsal Players. Sports, 7(3), 69. https://doi.org/10.3390/sports7030069

Marques, M. C., Pereira, A., Reis, I. G., \& van den Tillaar, R. (2013). Does an in-season 6-week combined sprint and jump training program improve strength-speed abilities and kicking performance in young soccer players? J Hum Kinet, 39(1), 157-166. https://doi.org/10.2478/hukin-2013-0078

McMillan, K., Helgerud, J., Macdonald, R., \& Hoff, J. (2005). Physiological adaptations to soccer specific endurance training in professional youth soccer players. Br J Sports Med, 39(5), 273-277. https://doi.org/10.1136/bjsm.2004.012526

Melchiorri, G., Ronconi, M., Triossi, T., Viero, V., De Sanctis, D., Tancredi, V., . . Alvero Cruz, J. R. (2014). Detraining in young soccer players. J Sports Med Phys Fitness, 54(1), 27-33.

Meylan, C. M., Cronin, J. B., Oliver, J. L., Hopkins, W. G., \& Contreras, B. (2014). The effect of maturation on adaptations to strength training and detraining in 11-15-year-olds. Scand J Med Sci Sports, 24(3), e156-164. https://doi.org/10.1111/sms.12128

Moore, A., \& Murphy, A. (2003). Development of an anaerobic capacity test for field sport athletes. J Sci Med Sport, 6(3), 275-284. https://doi.org/10.1016/s1440-2440(03)80021-x

Ratel, S., Duche, P., Hennegrave, A., Van Praagh, E., \& Bedu, M. (2002). Acid-base balance during repeated cycling sprints in boys and men. J Appl Physiol (1985), 92(2), 479-485. https://doi.org/10.1152/japplphysiol.00495.2001 
Rebelo, A., Brito, J., Maia, J., Coelho-e-Silva, M. J., Figueiredo, A. J., Bangsbo, J., . . Seabra, A. (2013). Anthropometric characteristics, physical fitness and technical performance of under-19 soccer players by competitive level and field position. Int $J$ Sports Med, 34(4), 312-317. https://doi.org/10.1055/s-0032-1323729

Rodríguez-Fernández, A., Sánchez-Sánchez, J., Ramirez-Campillo, R., Rodríguez-Marroyo, J. A., Villa Vicente, J. G., \& Nakamura, F. Y. (2018). Effects of short-term in-season break detraining on repeated-sprint ability and intermittent endurance according to initial performance of soccer player. PLoS One, 13(8), e0201111. https://doi.org/10.1371/journal.pone.0201111

Rodriguez-Rosell, D., Franco-Marquez, F., Mora-Custodio, R., \& Gonzalez-Badillo, J. J. (2016). The effect of high-speed strength training on physical performance in young soccer players of different ages. J Strength Cond Res. https://doi.org/10.1519/jsc.0000000000001706

Salah, G., Cavar M, \& Hofmann P. (2017). The Effects of Agility Type Sprint Interval Training and Continuous Training on Aerobic and Anaerobic Capabilities of Young Soccer Players. J Athl Enhanc, 6(2). https://doi.org/10.4172/2324-9080.1000254

Sperlich, B., De Marées, M., Koehler, K., Linville, J., Holmberg, H. C., \& Mester, J. (2011). Effects of 5 weeks of high-intensity interval training vs. volume training in 14 -year-old soccer players. J Strength Cond Res, 25(5), 1271-1278. https://doi.org/10.1519/jsc.0b013e3181d67c38

Stølen, T., Chamari, K., Castagna, C., \& Wisløff, U. (2005). Physiology of soccer: an update. Sports Med, 35(6), 501-536. https://doi.org/10.2165/00007256-200535060-00004

Strøyer, J., Hansen, L., \& Klausen, K. (2004). Physiological profile and activity pattern of young soccer players during match play. Med Sci Sports Exerc, 36(1), 168-174. https://doi.org/10.1249/01.mss.0000106187.05259.96

Taşkin, H. (2009). Effect of circuit training on the sprint-agility and anaerobic endurance. J Strength Cond Res, 23(6), 1803-1810. https://doi.org/10.1519/jsc.0b013e3181b3dfc0

Tønnessen, E., Shalfawi, S. A., Haugen, T., \& Enoksen, E. (2011). The effect of 40-m repeated sprint training on maximum sprinting speed, repeated sprint speed endurance, vertical jump, and aerobic capacity in young elite male soccer players. J Strength Cond Res, 25(9), 2364-2370. https://doi.org/10.1519/jsc.0b013e3182023a65

Torres-Torrelo, J., Rodriguez-Rosell, D., Mora-Custodio, R., Pareja-Blanco, F., Yanez-Garcia, J. M., \& Gonzalez-Badillo, J. J. (2018). Effects of Resistance Training and Combined Training Program on Repeated Sprint Ability in Futsal Players. Int J Sports Med, 39(7), 517-526. https://doi.org/10.1055/a0596-7497

Turner, A. N., \& Stewart, P. F. (2014). Strength and Conditioning for Soccer Players. Strength Cond J, 36(4), 1-13. https://doi.org/10.1519/ssc.0000000000000054

Vaeyens, R., Malina, R. M., Janssens, M., Van Renterghem, B., Bourgois, J., Vrijens, J., \& Philippaerts, R. M. (2006). A multidisciplinary selection model for youth soccer: the Ghent Youth Soccer Project. Br J Sports Med, 40(11), 928-934; discussion 934. https://doi.org/10.1136/bjsm.2006.029652

Vanderford, M. L., Meyers, M. C., Skelly, W. A., Stewart, C. C., \& Hamilton, K. L. (2004). Physiological and sport-specific skill response of olympic youth soccer athletes. J Strength Cond Res, 18(2), 334342. https://doi.org/10.1519/r-11922.1

Wong, P. L., Chamari, K., \& Wisloff, U. (2010). Effects of 12-week on-field combined strength and power training on physical performance among U-14 young soccer players. J Strength Cond Res, 24(3), 644-652. https://doi.org/10.1519/jsc.0b013e3181ad3349 


\section{(c) (1) 99}

This work is licensed under a Attribution-NonCommercial-NoDerivatives 4.0 International (CC BY-NC-ND 4.0). 